\title{
PengembanganVirtual Reality Untuk Mendigitalisasi Situs Peninggalan Sejarah Masjid Agung Banten
}

\author{
Muhammad Subali ${ }^{1}$,Hadi Rahmadi ${ }^{2}$ \\ Miftah Andriansyah ${ }^{3}$,Imam Purwanto ${ }^{4}$ \\ Edi Junaedi $^{5}$,Antonius Irianto ${ }^{6}$, Debyo Saptono ${ }^{7}$ \\ ${ }^{1}$ Teknik Informatika, Sekolah Tinggi Teknik Multimedia Cendekia Abditama \\ ${ }^{2}$ Teknik Informatika, Sekolah Tinggi Teknik Multimedia Cendekia Abditama \\ ${ }^{3}$ Teknik Informatika, sekolah Tinggi Teknik Multimedia Cendekia Abditama \\ ${ }^{4}$ Teknik Informatika, Sekolah Tinggi Teknik Multimedia Cendekia Abditama \\ ${ }^{5}$ Teknik Informatika, Sekolah Tinggi Teknik Multimedia Cendekia Abditama \\ ${ }^{6}$ Teknik Elektro, Sekolah Tinggi Teknik Multimedia Cendekia Abditama \\ ${ }^{7}$ Teknik Elektro, Sekolah Tinggi Teknik Multimedia Cendekia Abditama \\ e-mail: ${ }^{1}$ subali@ cendekia.ac.id, ${ }^{2}$ hadi@ cendekia.ac.id, ${ }^{3}$ miftahandriansyah@gmail.com, \\ Imampur2002@yahoo.com, ${ }^{5}$ edi@cendekia.ac.id, ${ }^{6}$ Antonius.irianto@gmail.com
}

\begin{abstract}
Abstrak
Pada masa modern ini hampir semua kegiatan kita tidak lepas dari yang namanya teknologi, perkembangan teknologi merupakan faktor utama yang mempengaruhi setiap elemen manusia. Salah satunya pada sektor arsitektur dan pariwisata yang sudah memanfaatkan teknologi digital untuk melakukan berbagai kegiatan. Virtual Reality merupakan teknologi terbaru yang dapat menghasilkan suasana realistis tiga dimensi, dan dapat membuat pengguna berinteraksi dengan lingkungan virtual. Virtual Reality merupakan sebuah teknologi yang menarik, yang dapat mengubah secara mendasar bagaimana kita berinteraksi dengan informasi.

Dalam penulisan ini, penulis menggunakan teknologi Virtual Reality untuk membuat suatu tempat bersejarah yang ada di Banten yaitu Masjid Agung Banten yang akan dijalankan pada PC. Penulis menggunakan aplikasi SketchUp dan Unity untuk membangun objek bangunan 3D dan merealisasikannya menjadi sebuah aplikasi Virtual Reality.
\end{abstract}

Kata kunci: Aplikasi, Banten, Masjid Agung Banten, Virtual Reality

Abstract

In this modern period almost all of our activities can not be separated from the name of technology, technological development is a major factor that affects every human element. One of them in the field of architecture and tourism that has been utilizing digital technology to perform various activities. Virtual Reality is the latest technology that can generate realistic three- dimensional atmosphere, and can make users interact with the virtual envi-ronment. Virtual Reality is an exciting technology that can fundamentally change how we interact with information.

In this writing, the author uses Virtual Reality technology to create a place that is in Banten, Banten Grand Mosque that will run on the PC.The author uses SketchUp and Unity applications to build $3 D$ building objects and make them into Virtual Reality applications.

Keywords: Applications, Banten, Banten Great Mosque, Virtual Reality 


\section{PENDAHULUAN}

Pariwisata merupakan salah satu sektor ekonomi penting di Indonesia. Salah satu pariwisata yang banyak dikunjungi yaitu tempat-tempat bersejarah karena memiliki nilai dan peran penting. Di Indonesia ada begitu banyak tempat pariwisata bersejarah yang dapat dikunjungi, salah satunya yaitu Masjid Agung Banten yang terletak di Desa Banten Lama, tepatnya di desa Banten, sekitar $10 \mathrm{~km}$ sebelah Utara Kota Serang.

Masjid Agung Banten merupakan masjid yang dibangun pada saat kejayaan Kesultanan Banten, Kesultanan yang akhirnya hancur dengan hanya menyisakan Masjid Agung Banten ini. Masjid Agung Banten merupakan objek wisata ziarah menarik karena memiliki arsitektur gayabangunan yang unik. Setiap harinya Masjid Agung Banten banyak dikunjungi para peziarah yang datang tidak hanya dari Banten saja, tetapi juga dari berbagai daerah pulau Jawa.

Hal menarik pertama adalah dari bangunan utama Masjid, yang dibangun pertama kali oleh Sultan Maulana Hasanuddin (1552-1570), sultan pertama Kesultanan Demak yang juga putra pertama Sunan Gunung Jati, itu adalah atapnya yang tumpuk lima. Menurut tradisi, rancangan bangunan utama masjid yang beratap tumpuk lima ini dipercayakan kepada arsitek Cina bernama Cek Ban Cut. Selain jumlah tumpukan, bentuk dan ekspresinya juga menampilkan keunikan yang tidak ditemui kesamaannya dengan masjid-masjid di sepanjang Pulau Jawa, bahkan di seluruh Indonesia.

Virtual reality adalah sebuah teknologi yang membuat pengguna atau user dapat berinteraksi dengan lingkungan yang disimulasikan oleh komputer, sehingga pengguna merasa berada di dalam lingkungan tersebut. Virtual Reality merupakan inovasi untuk pengenalan lingkungan secara virtual dengan teknologi yang dapat menghasilkan suasana realistis tiga dimensi. Virtual Reality merupakan sebuah teknologi yang menarik, yang dapat mengubah secara mendasar bagaimana kita mengenal dan berinteraksi dengan informasi. [1]

Virtual Reality dapat dimanfaatkan sebagai objek pembelajaran, informasi, dan juga promosi periklanan. Manfaat Virtual Reality pada informasi dapat menampilkan informasi secara virtual seperti menampilkan bangunan bersejarah, dan tempat wisata, dan bangunan. Pemanfaatan teknologi Virtual Reality saat ini memang belum banyak diterapkan, terutama dalam informasi tempat wisata ziarah.[4]

Banten merupakan gugusan beberapa situs bangunan bersejarah masa Kesultanan Banten. Masjid Agung Banten adalah tempat utama pusat persebaran Islam di Banten, Masjid ini utuh dan kokoh hingga sekarang.[7] Karena itu penulis bertujuan merancang aplikasi Virtual Reality Masjid Agung Banten ini guna menambah informasi, dan pengetahuan serta menjadi dokumentasi digital warisan budaya Banten. Pengembangan aplikasi ini merupakan wujud tri dharma Perguruan Tinggi Sekolah Tinggi Teknik Cendekia bekerja sama dengan Pemprov Banten.[3]

\section{METODE PENELITIAN}

Pada penelitian ini penulis menggunakan serangkaian metode untuk memudahkan pembuatan aplikasi. Tahapan yang digunakan adalah sebagai berikut:[2]

\subsection{Studi Pustaka}

Pada tahap ini, penulis mencari literatur yang berkaitan dengan Masjid Agung Banten, pembuatan model bangunan, dan teknologi Virtual Reality yang didapat dari buku-buku dan internet. 


\subsection{Perencanaan}

Pada tahap ini, merupakan tahap pembangunan model-model tiga dimensi seperti modeling, texturing, serta exporting perancangan model 3D menggunakan software SketchUp 2017.[8]

\subsection{Implementasi}

Setelah model 3D selesai selanjutnya diimpementasikan menjadi aplikasi Virtual Reality dengan software Unity serta software pendukung lain untuk membangun fitur-fitur aplikasi.

\subsection{Ujicoba}

Tahap ini dilakukan untuk melihat sejauh mana aplikasi yang telah dirancang dan kemudian dibangun berfungsi dengan semestinya, sesuai dengan tujuan.

\section{PERANCANGAN}

Aplikasi yang dibuat oleh penulis merupakan sebuah program sederhana dimana user dapat melihat gambaran sebuah bangunan Masjid Agung Banten dan masuk ke dalamnya di dunia virtual tiga dimensi dengan panorama 360 derajat.[5] Pada program ini penulis menggunakan kontrol keyboard dan mouse untuk menggerakan kamera sehingga user dapat melihat seisi bangunan. Desain pemodelantiga dimensi dibuat dengan menggunakan software SketchUp selanjutnya diolah menggunakan software Unity.[6] Dengan fitur Unity dapat mengontrol objek sehingga memberikan respon dari suatu kondisi dan kejadian tertentu, seperti dapat berjalan serta menoleh ke kanan dan kiri sesuai dengan keinginan user.

3.1. Spesifikasi Perangkat Lunak dan Perangkat Keras yang digunakan

a. Spesifikasi Perangkat Keras yang Digunakan:

- PC All in One - HP

- Prosesor Intel ${ }^{\circledR}$ Core TM i5 4460T @ 1,9 GHz

- RAM $4 G B$

- $\quad$ Hard disk 1 Tera

b. Spesifikasi Perangkat Lunak yang digunakan

- $\quad$ SketchUp 2017

- Unity versi 5.6.2p2 (64-bit)

\subsection{Tahapan Pembuatan Virtual Reality}

Dalam pembuatan program Virtual Reality Masjid Agung Banten ini ada beberapa tahapan yaitu: 


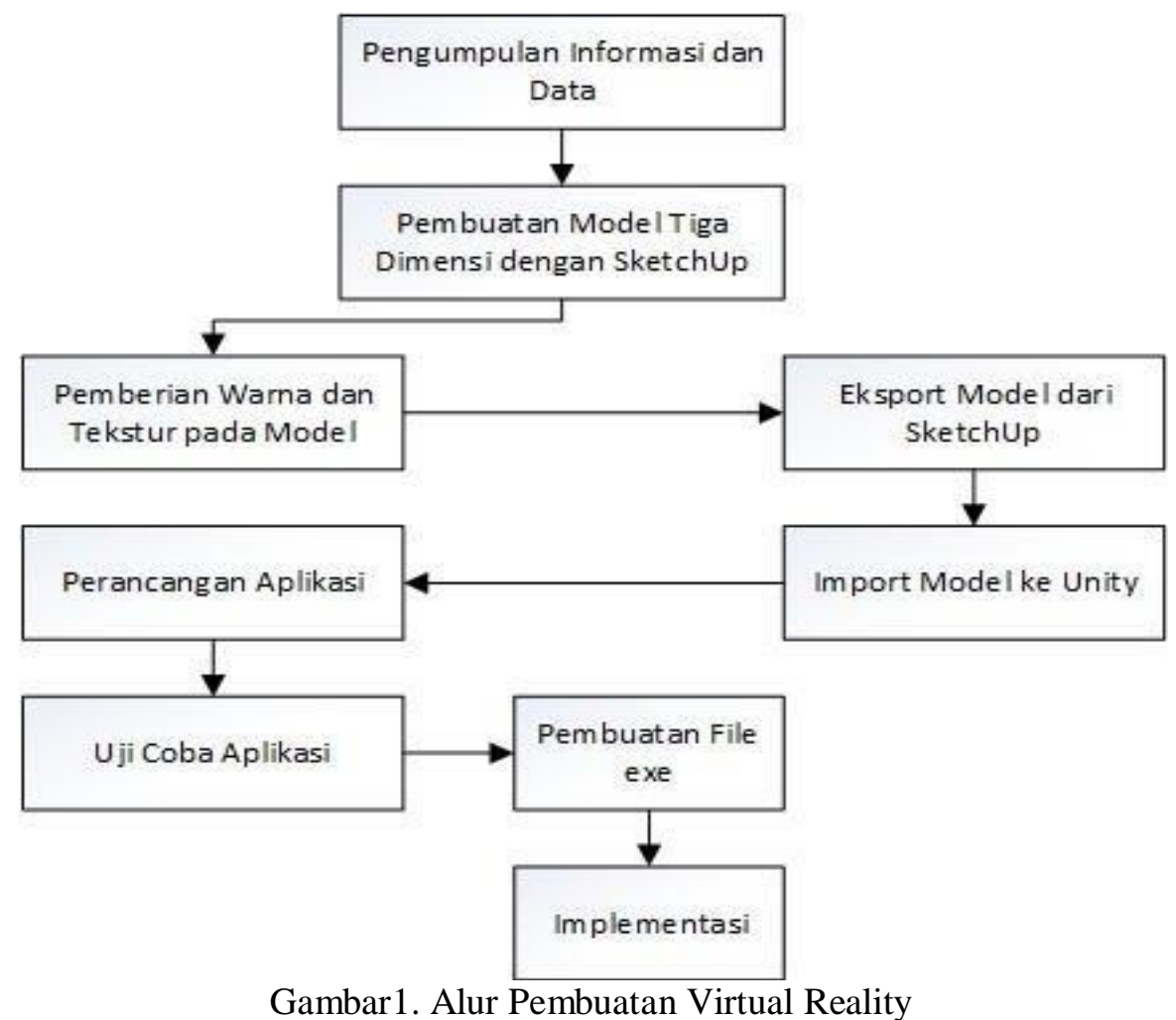

- Pengumpulan Informasi dan Data

Pengumpulkan informasi yang dapat digunakan sebagai bahan untuk perencanaan tahap awal pembuatan Masjid Agung Banten ini adalah mengumpulkan informasi dan data mulai dari sejarah, peta Masjid, bentuk Masjid, Tempat Wudhu, Menara, Pagar, hingga Gerbang, yang didokumentasi dalam bentuk foto dan video.

- Pembuatan Model Tiga Dimensi dengan SketchUp

Pada tahap ini dilakukan pembuatan model tiga dimensi Masjid Agung Banten dengan menggunakan aplikasi SketchUp 2017. Model yang dibuat meliputi Masjid, Tempat Wudhu, Menara, Pagar, Gerbang, serta objek lain didalamnya.

- Pemberian Warna dan Tekstur pada Model

Setelah semua pembuatan model Masjid Agung selesai, kemudian pemberian warna dan tekstur pada masing - masing model dari bangunan di SketchUp. Warna diberikan sesuai aslinya, agar terlihat sama antara model tiga dimensi dengan aslinya. Sketchup menyediakan beberapa material yang dapat diaplikasikan dalam model Sketchup namun ada beberapa material yang belum ada sehingga penulis menggunakan foto yang telah didokumentasi sebagai tekstur material agar bangunan terlihat seperti aslinya.

- Eksport dari SketchUp

Pada tahap ini model yang telah selesai dibuat di SketchUp selanjutnya di eksport dalam bentuk format file .fbx karena .fbx untuk objek yang memiliki texture, animasi, dan 3D agar model 3D dapat dibaca oleh Unity dalam bentuk file 3D. File yang telah di eskport dari SketchUp ada dalam bentuk file .fbx dan folder material yang berisi tekstur dan selanjutnya akan di import ke Unity.

- Import Model ke Unity

Pada tahap ini merupakan tahap pemindahan file .fbx dan folder material yang telah di eksport dari SketchUp kedalam Game Engine Unity 3D. Pada tahap ini penulis menambahkan beberapa fitur agar aplikasi virtual reality ini terlihat lebih nyata dan menarik, salah 
satunya menambahkan sky box yang berfungsi sebagai langit, serta penambahan character controller yang berfungsi sebagai gerak saat aplikasi dijalankan, karena pada aplikasi ini arah kamera dapat berputar 360 derajat, lalu penambahan objek seperti pohon dan juga directional light atau bisa disebut juga sebagai arah sinar matahari.

- Tahap Pengujian Aplikasi

Tahap uji coba aplikasi ini dilakukan guna untuk menguji debug and error aplikasi Virtual Reality Masjid Agung Banten yang telah dibuat.

- Pembuatan File Extensi Exe

Tahap ini untuk memastikan sudah tidak ada error dalam aplikasi yang dibuat, jika sudah tidak ada error maka aplikasi di build menjadi file ekstensi.exe.

- Implementasi Aplikasi

Ini merupakan tahap akhir dari pembuatan aplikasi Virtual Reality. Dari file berekstensi.exe yang telah dibuat akan di implementasikan untuk membantu user melihat desain Masjid Agung Banten secara langsung dalam bentuk model tiga dimensi.

1. Flowchart Alur Aplikasi

Pada tahap ini merupakan proses tahapan alur jalannya aplikasi Virtual Reality yang akan dibuat dan menghasilkan tujuan seperti pada gambar 2 .

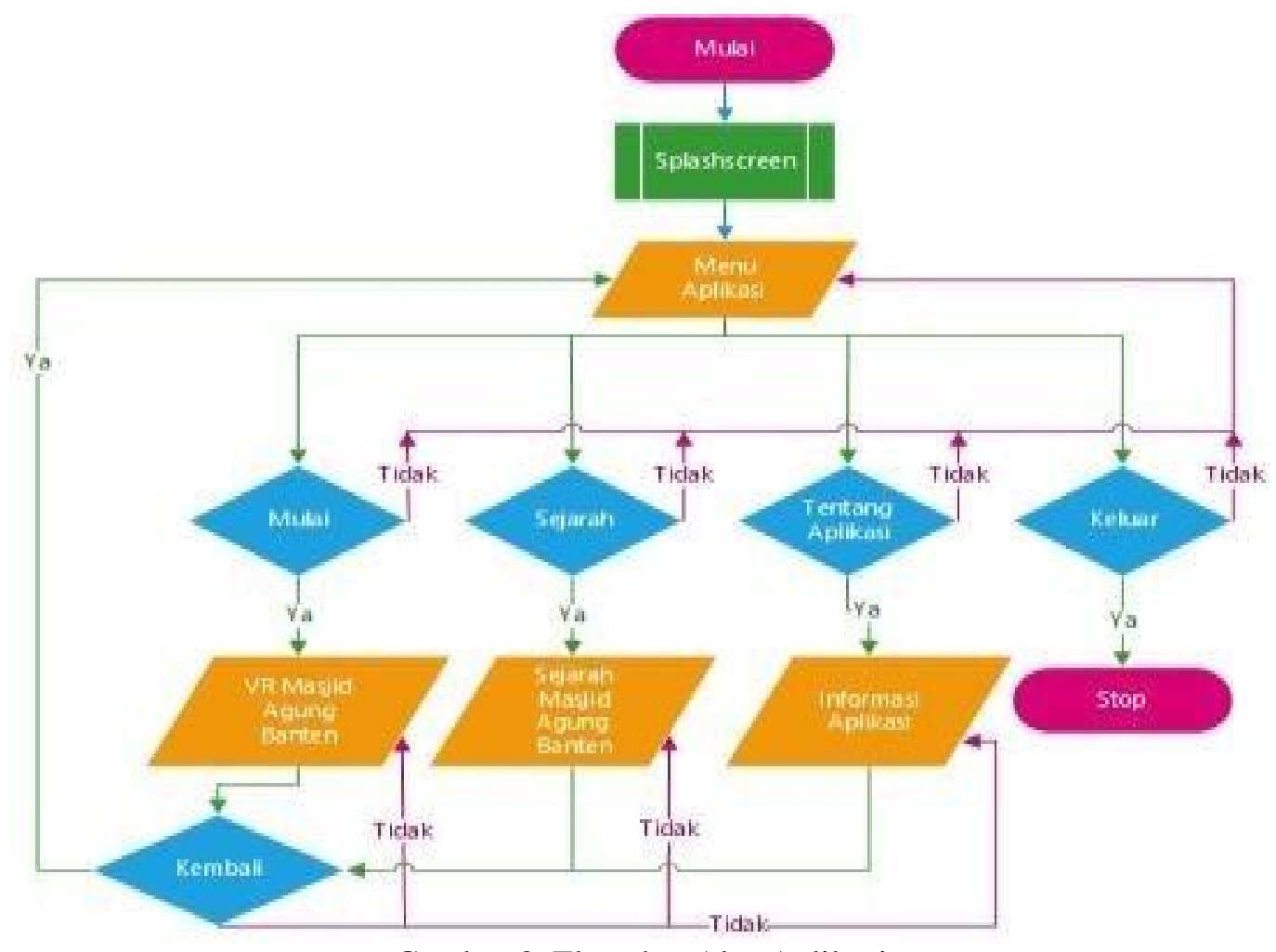

Gambar 2. Flowchat Alur Aplikasi

- Pada langkah awal, user memulai aplikasi Virtual Reality Masjid AgungBanten dengan cara klik file executable untuk menjalankan aplikasi.

- Aplikasi akan menampilkan splash screen kurang lebih selama empatdetik yaitu menampillkan logo Provinsi Banten.

- Selanjutnya aplikasi akan menampilkan beberapa pilihan "Menu" dimana user dapat memilih tombol "Mulai", tombol "Sejarah", tombol "Tentang Aplikasi", dan tombol "Keluar". 
- Jika user menekan tombol "Mulai" maka aplikasi menampilkan VirtualReality Masjid Agung Banten dengan sudut kamera 360 derajat yang dapat melihat ke seluruh bangunan, jika user tidak menekan tombol apapun maka masih pada tampilan "Menu Aplikasi". Saat di klik tombol "Mulai" user dapat memilih kembali ke "Menu Aplikasi" dengan menekan tombol "Kembali".

- Jika user menekan tombol "Sejarah" maka aplikasi menampilkan tekssejarah Masjid Agung Banten, jika user tidak menekan tombol apapun maka masih pada tampilan "Menu Aplikasi". Saat di klik tombol "Sejarah" akan menampilkan teks sejarah dan user dapat memilih kembali ke "Menu Aplikasi" dengan menekan tombol "Kembali".

- Jika user menekan tombol "Tentang Aplikasi" maka aplikasi menam-pilkan teks tentang perancang aplikasi, sumber background, dan background instrumental aplikasi, jika user tidak menekan tombol apapun maka masih pada tampilan "Menu Aplikasi". Saat di klik tombol "Tentang Aplikasi" akan menampilkan sejarah dan user dapat memilih kembali ke "Menu Aplikasi" dengan menekan tombol "Kembali".

- Jika user menekan tombol "Keluar" maka aplikasi akan keluar dari aplikasi.

\section{IMPLEMENTASI}

Pada bagian sub bab ini akan dibahas tentang pembuatan objek Masjid Agung Banten beserta objek lainnya. Untuk pembuatan objek 3D menggunakan software SketchUp.

Untuk proses pembuatannya akan dibagi menjadi beberapa bagian, mulai dari mengambil lokasi peta Masjid Agung Banten, pembuatan lantai, dinding, pintu, jendela, mimbar, dan segala objek yang ada di dalam Masjid, menara masjid, hingga yang terakhir adalah pembuatan atap Masjid

1. Penyatuan Objek dan Proses Eksport Setelah semua model 3D dibuat, selanjutnya yaitu tahap penyatuan objek menjadi satu, tata letak dan desain dibuat semirip mungkin seperti aslinya, lihat pada gambar 3 .

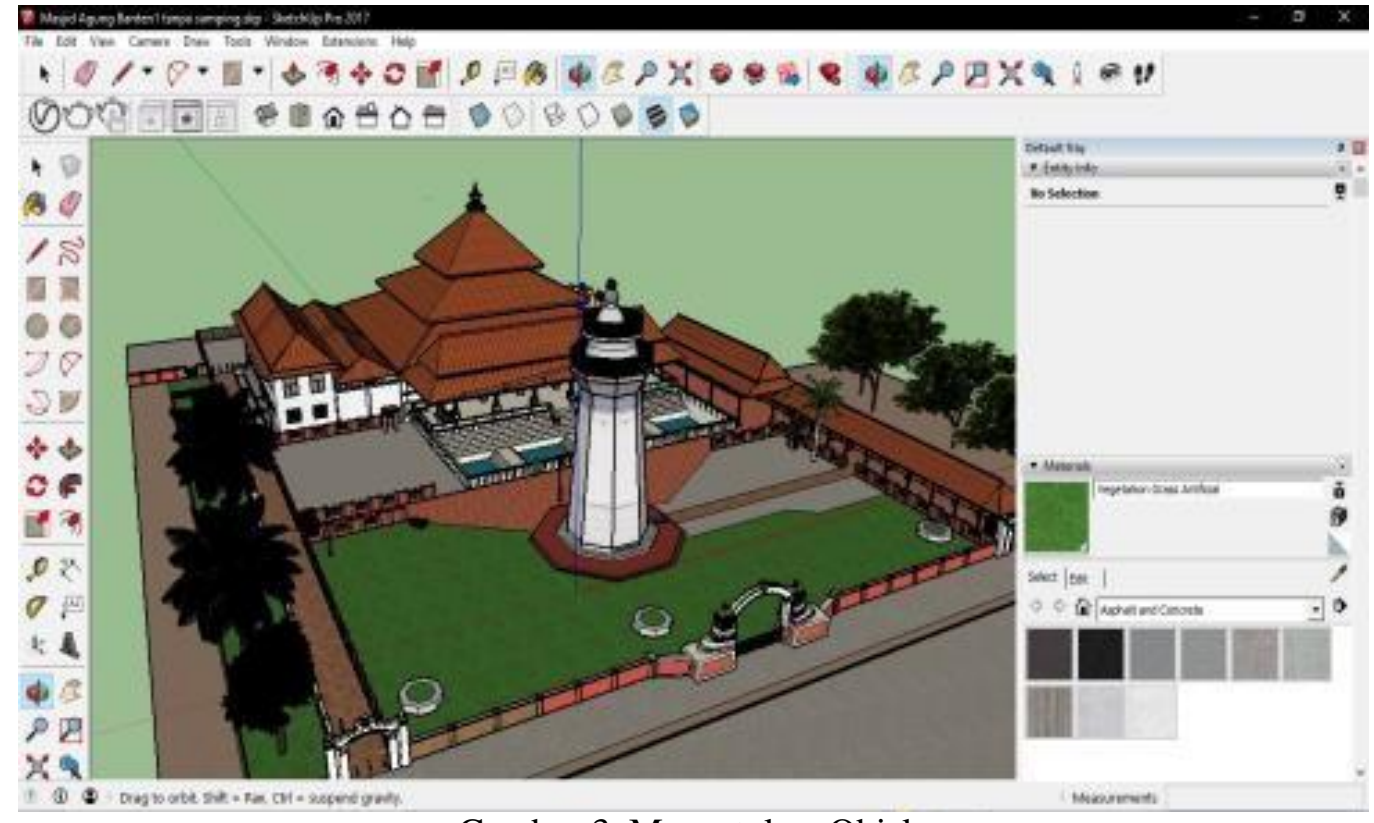

Gambar 3. Menyatukan Objek

Selanjutnya proses export, File > Export $>$ 3D Models, lalu pilih Options > ikuti pengaturan seperti pada gambar 4, lalu pilih export. 


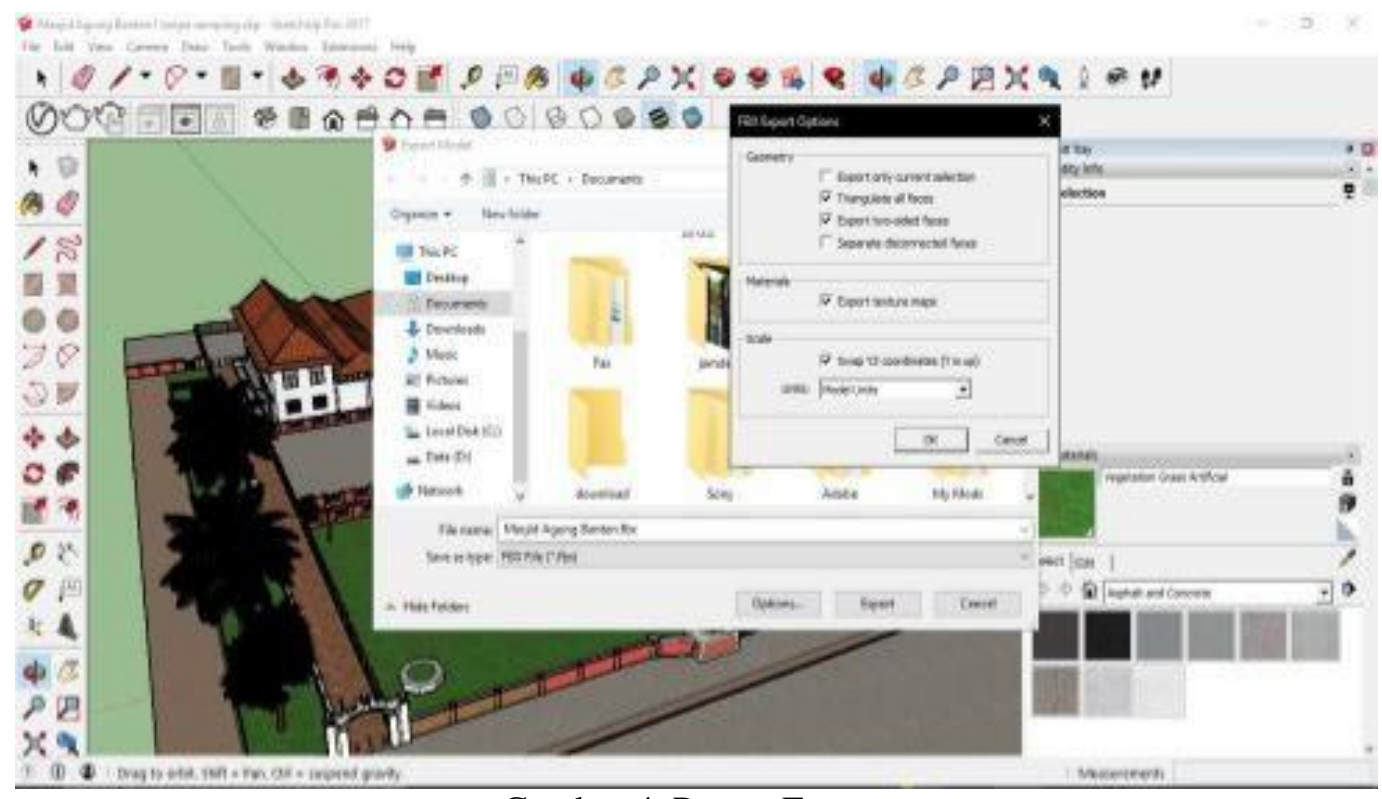

Gambar 4. Proses Export

Setelah proses export selesai selanjutnya proses convert file agar file .fbx yang telah di export ukurannya menjadi lebih kecil. Jalankan software Autodesk FBX Converter x64 2013 selanjutnya Add > pilih file fbx yang telah di export > Convert.

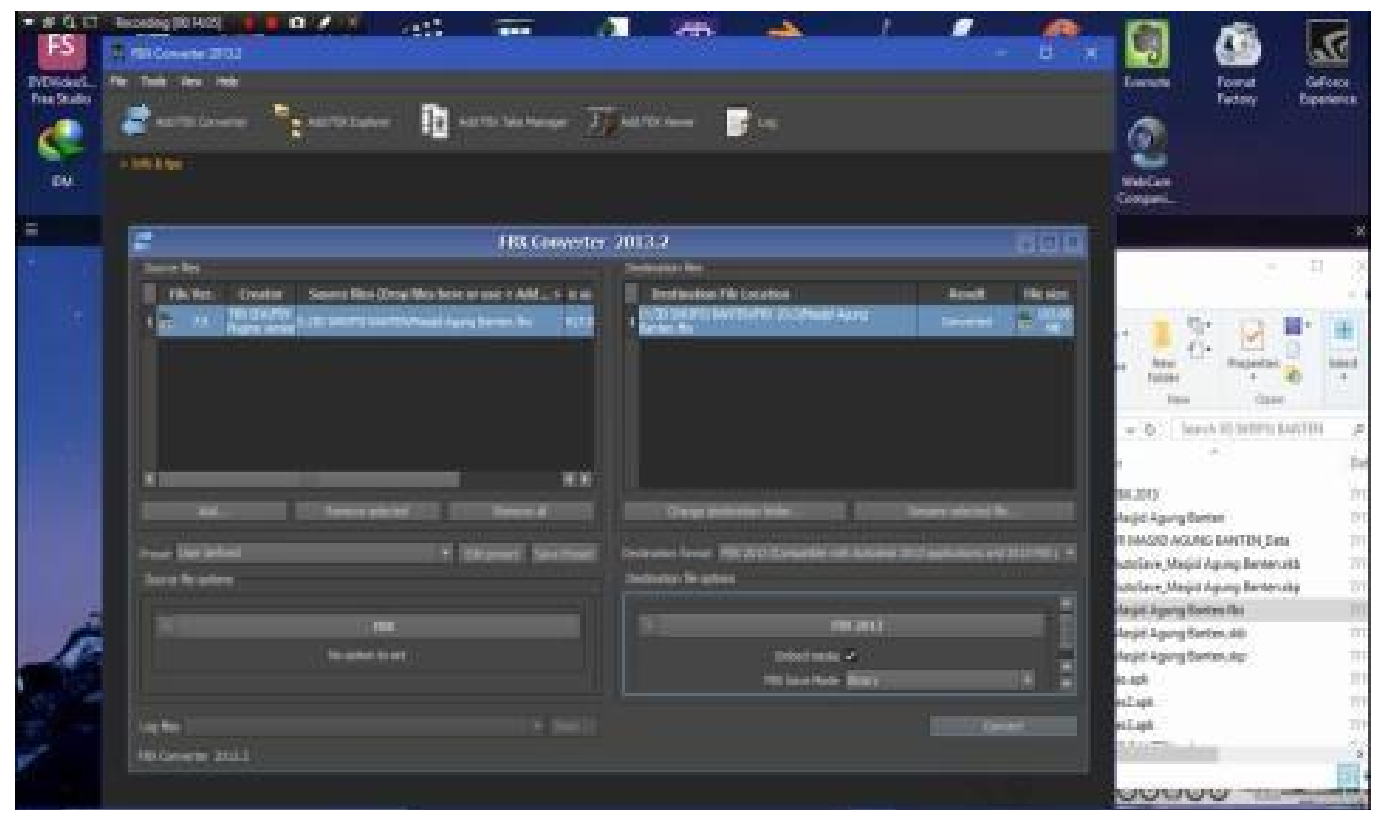

Gambar 5. Proses Convert

2. Perancangan Aplikasi

a. Import Project

Tahap selanjutnya, buka aplikasi Unity lalu untuk membuat project baru baru berikut ini adalah langkah-langkahnya, buka Unity, lalu pada Unity > clik New beri nama project. Lihat gambar 6. 


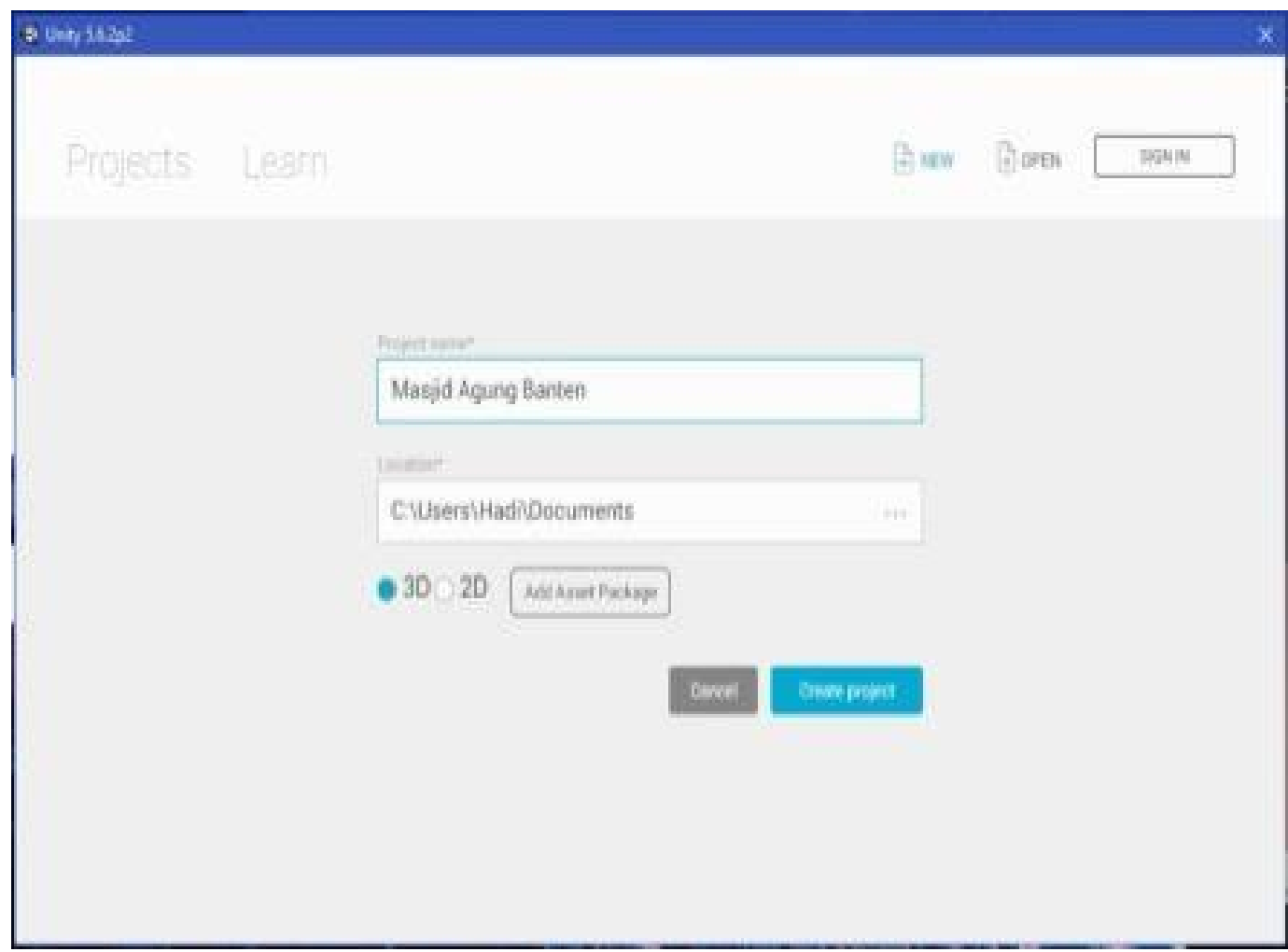

Gambar 6. Pembuatan Projek Baru

b. Uji Coba Aplikasi

Setelah semua selesai maka tahap akhir adalah untuk uji coba aplikasi. Saat tombol play ditekan maka user akan ke mode game, dan user akan menggunakan fitur First Person Controller yang telah dimasukkan ke dalam project sebelumnya, dengan tombol navigasi $\mathrm{W}, \mathrm{A}$, S, D, untuk bergerak ke depan, kiri, belakang, dan kanan.

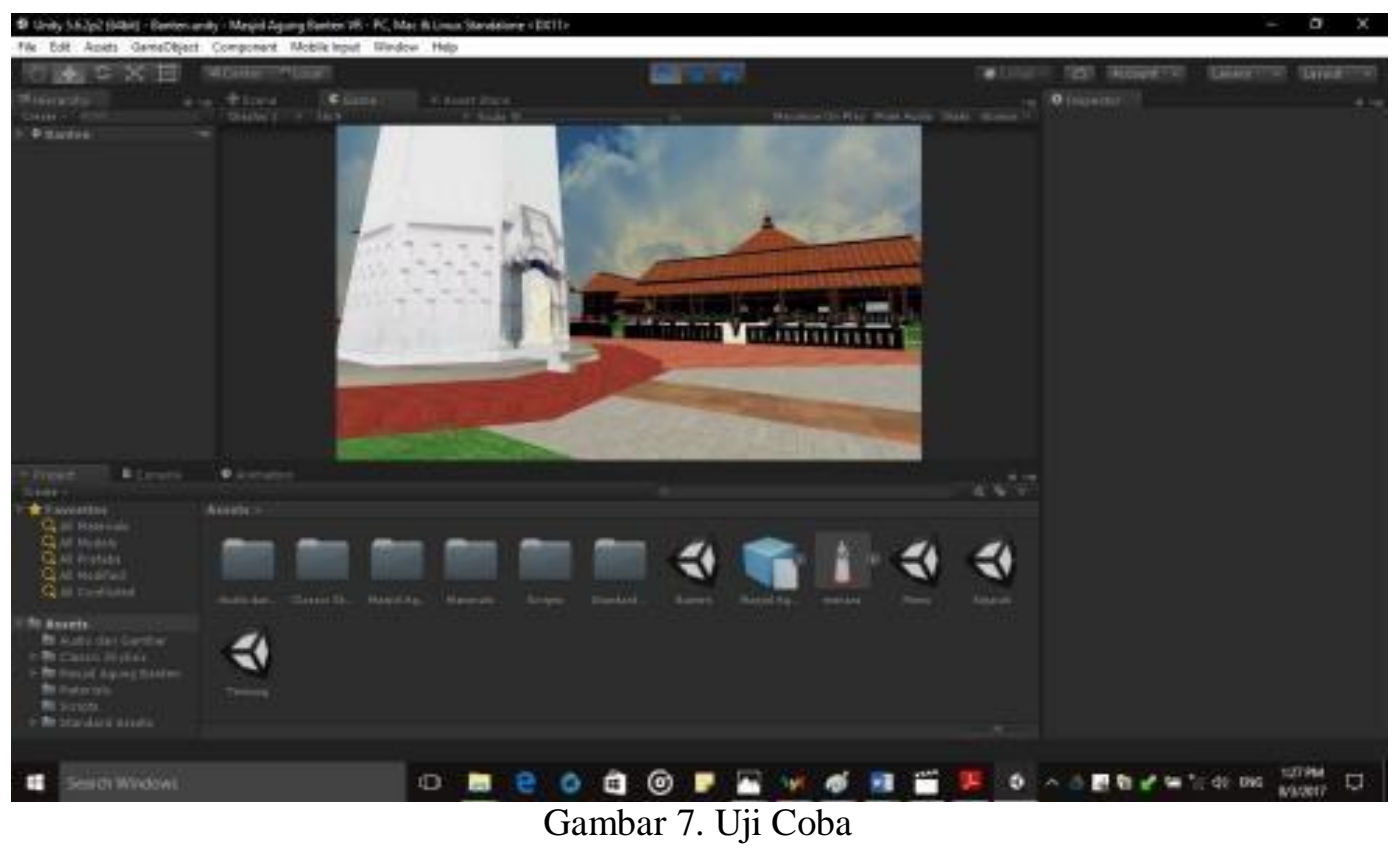


c. Pembuatan File Ekstensi Exe

Pada tahap selanjutnya yaitu pembuatan file executable tahap dimana telah memastikan bahwa aplikasi yang dibuat sudah tidak ada error dan sudah layak untuk digunakan. Untuk membuat file executable caranya klik File > Build Setting > Masukkan (drag) semua scene ke dalam secara berurutan ke Scenes In Build > Pilih Platform PC, Mac \& Linux Standalone.Kemudian klik build, kemudian akan muncul tampilan seperti gambar 8.

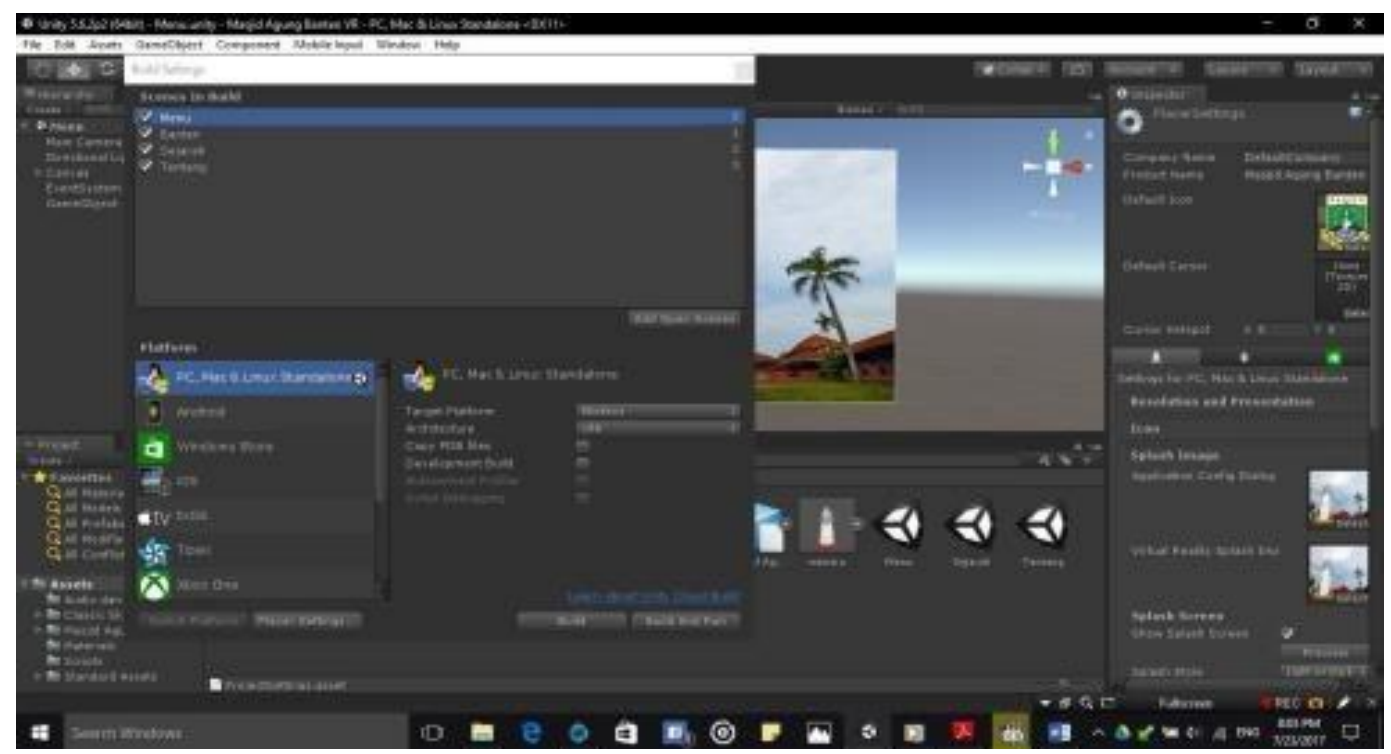

Gambar 8. Pembuatan File exe

Kemudian di tahap ini adalah proses building menjadi aplikasi, caranya klik build kemudian akan muncul file yang telah selesai di build lihat gambar 9 .

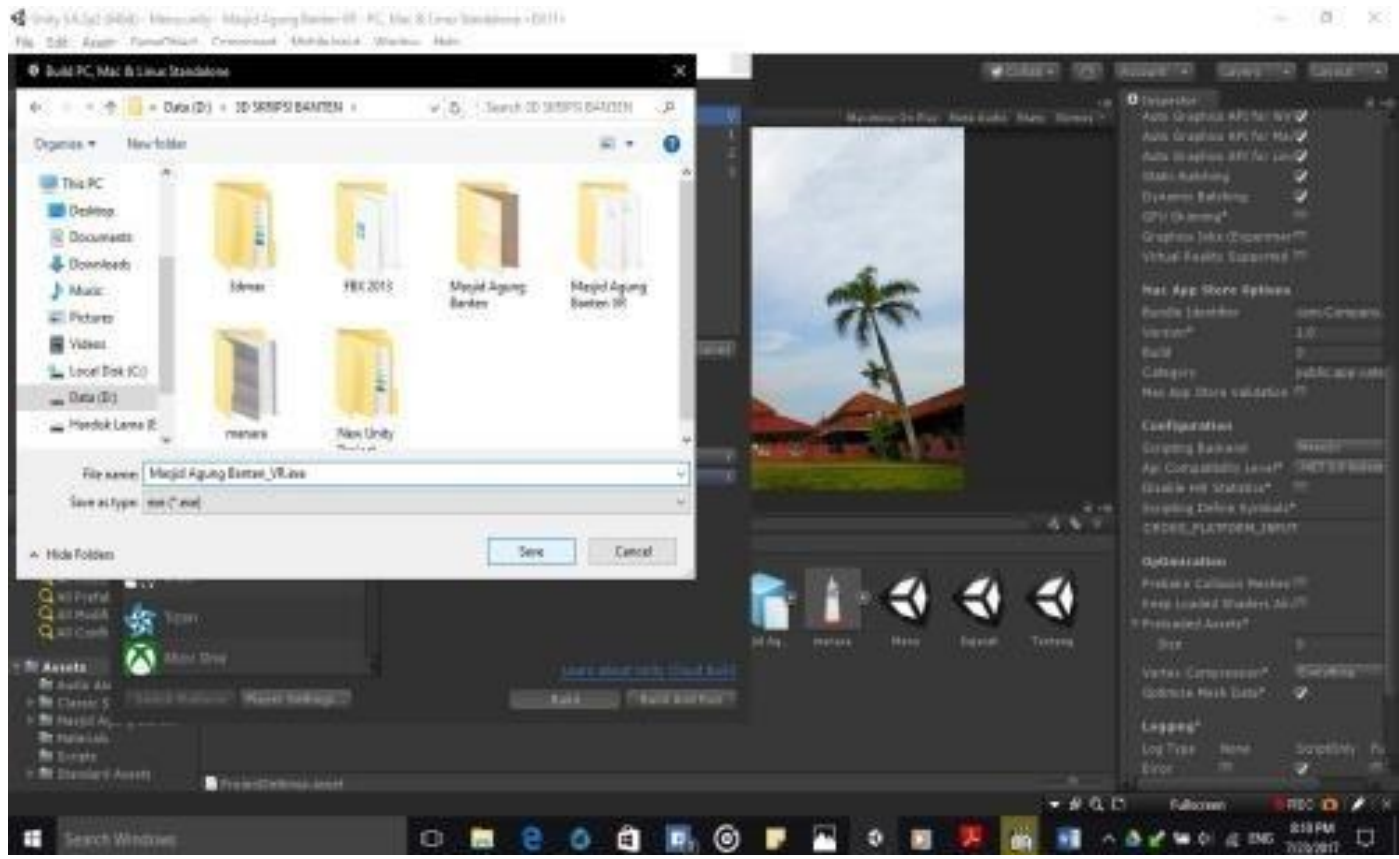

Gambar 9. Pemberian Nama Aplikasi Ekstensi exe

Subali et,al (PengembanganVirtual Reality Untuk Mendigitalisasi Situs Peninggalan Sejarah Masjid Agung Banten) 
d. Implementasi Aplikasi

Tahap akhir dalam pembuatan aplikasi Virtual Reality ini adalah tahap implementasi yang berbentuk executable file. Pada bagian ini aplikasi sudah dapat digunakan oleh user secara personal. Pengguna dapat melihat bentuk bangunan Masjid Agung Banten melalui aplikasi ini dan juga dapat menilai serta memberikan pendapat terhadap bangunan Masjid Agung Banten yang telah dibuat secara Virtual ini.

Hal yang perlu diperhatikan dalam aplikasi ini adalah spesifikasi komputer yang digunakan harus memenuhi kriteria minimal seperti pada Tabel 1.

Tabel 1. Spesifikasi Minimum untuk Menjalankan Aplikasi

\begin{tabular}{|c|c|c|c|}
\hline Sistem Operasi & Kartu Grafis & Prosesor & \\
\hline Windows: XP & Intel HD & 2.0 Ghz Dual & 2 GB atau di \\
SP2 atau & 4000 atau di & Core & atasnya \\
berikutnya; Mac & atasnya & Processor atau & \\
OS X "Snow & & di atasnya & \\
Leopard" 10.6 & & & \\
\hline
\end{tabular}

Jika kriteria pada Tabel 1 sudah terpenuhi maka pengguna dapat menjalankan aplikasi Virtual Reality ini dengan lancar. Berikut merupakan konfigurasi awal sebelum aplikasi berjalan. Lihat Gambar 10. 
Masjid Agung Banten VR Configuration

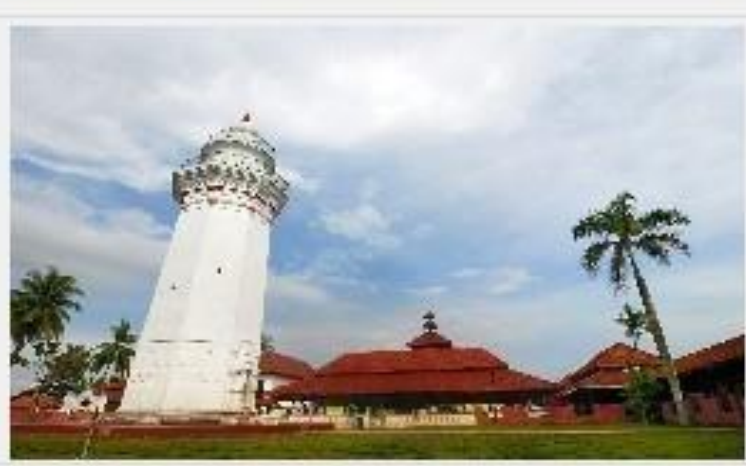

Graphics Input

\begin{tabular}{lll} 
Screen resolution & $1366 \times 768$ & $\square$ Windowed \\
Graphics quality & Fastest \\
Select monitor & Display 1 \\
\cline { 2 - 2 } &
\end{tabular}

Gambar 10. Konfigurasi Awal

Pada Gambar 10 di atas terdapat pengaturan Graphics \& Input. Pengaturan Graphics berguna untuk mengatur resolusi layar aplikasi dan kualitas grafik yang di inginkan. Sedangkan pada bagian Input terdapat keterangan tombol navigasi yang digunakan agar Controller dapat bergerak sesuai dengan keinginan pengguna.

Tekan tombol Play untuk memulai aplikasi. Lihat Gambar 6 yang menampilkan aplikasi saat sedang berjalan. Saat tombol Play ditekan maka user akan ke aplikasi Virtual Reality, dan user akan menggunakan dengan tombol navigasi W, A, S, D, untuk bergerak ke depan, kiri, belakang, dan kanan. 


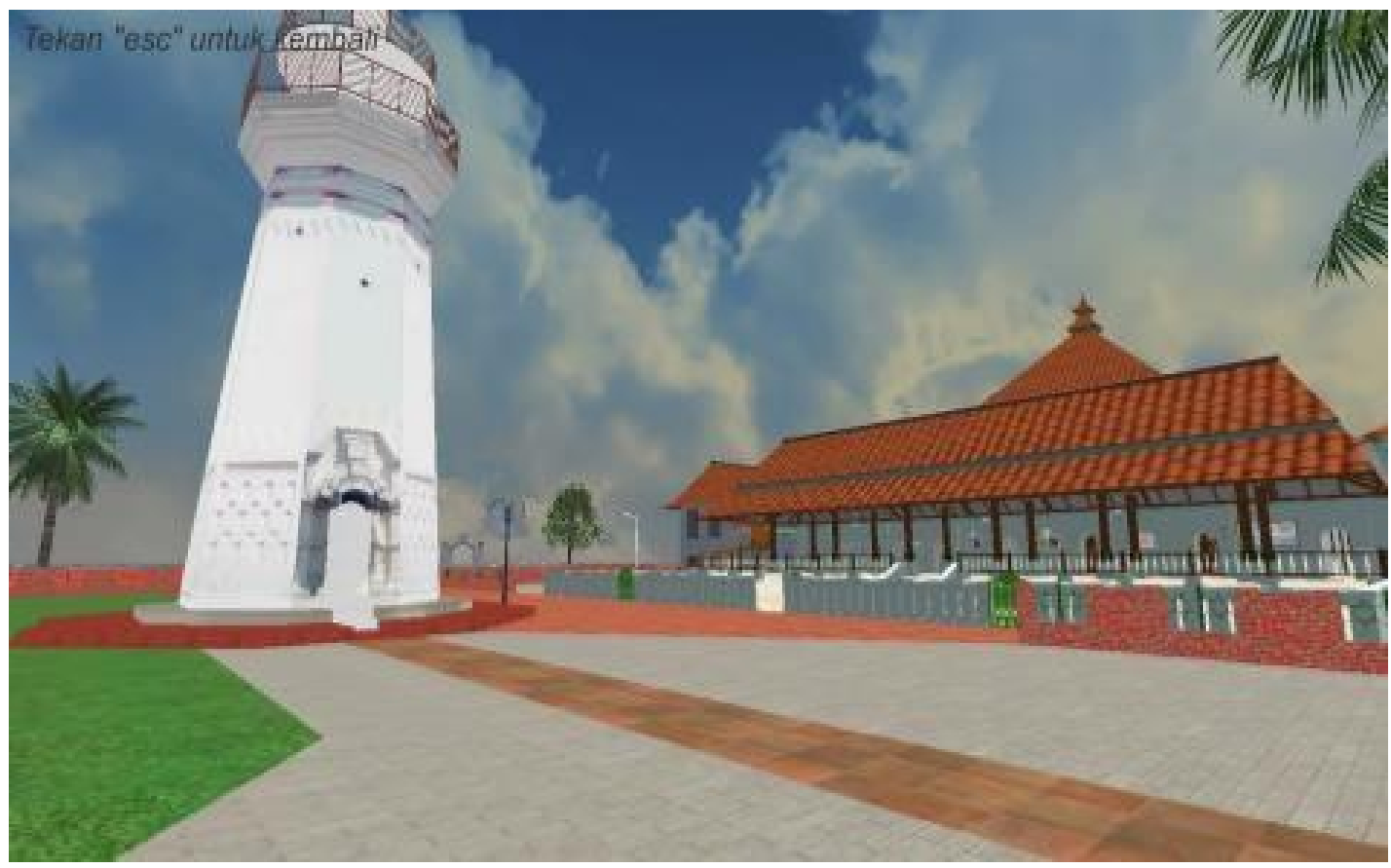

Gambar 11. Implementasi Aplikasi

e. Persentase Responden

Untuk menunjang penulisan, penulis melakukan survei hasil penelitian aplikasi terhadap 10 responden. Lihat tabel 2 dan gambar 12.

Tabel 2. Persentase Responden

\begin{tabular}{|c|l|c|}
\hline No & \multicolumn{1}{|c|}{ Pertanyaan } & Jumlah \\
\hline 1 & Aplikasi Mudah Digunakan & $98 \%$ \\
\hline 2 & Objek menyerupai bentuk yang sebenarnya & $96 \%$ \\
\hline 3 & Komposisi Warna Menarik & $98 \%$ \\
\hline 4 & Kendali Kamera Mudah Digunakan & $97 \%$ \\
\hline 5 & Informasi yang disajikan Jelas & $99 \%$ \\
\hline
\end{tabular}




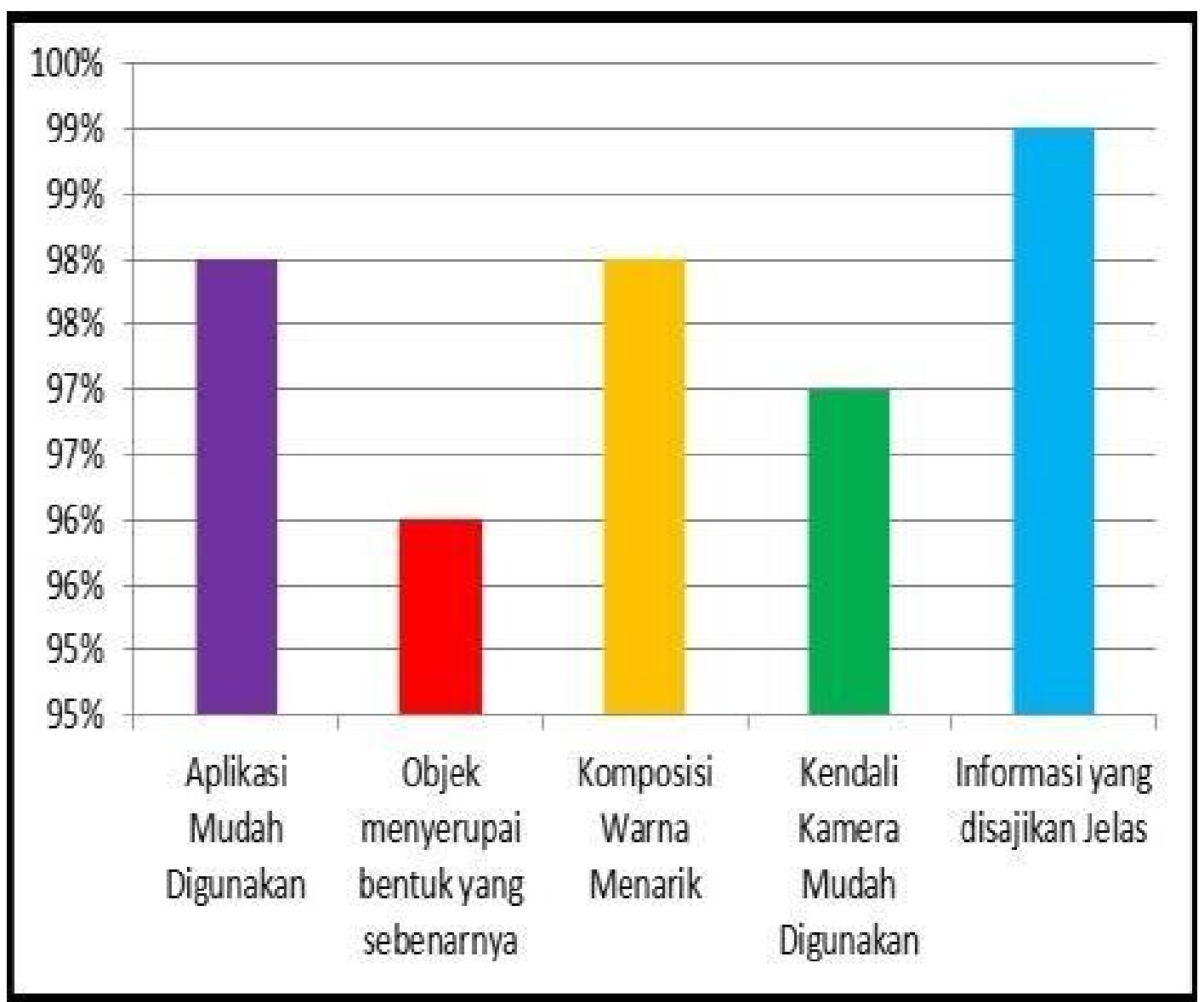

Gambar 12. Grafik Persentase Responden

\section{KESIMPULAN}

Virtual reality adalah sebuah teknologi yang membuat pengguna atau user dapat berinteraksi dengan lingkungan yang ada dalam dunia maya yang menampilkan tampilan 360 derajat. Dengan adanya aplikasi Virtual Reality Masjid Agung Banten ini dapat bermanfaat dan mempermudah sebagai media pengenalan lingkungan, pembelajaran peninggalan bangunan bersejarah, serta menambah pustaka digital di Banten. Modeling tiga dimensi menggunkan aplikasi SketchUp ini pada dasarnya adalah pembuatan objek dari sebuah rectangle, push/pull, cube, circle,dan tools lainnya seperti scale, extrude, dan rotate dapat dibentuk sebuah objek seperti yang diinginkan. Kemudian Unity digunakan untuk membangun aplikasi Virtual yang atraktif dan interaktif, dengan fitur yang terdapat pada Unity objek yang dibuat di SketchUp dapat diolah menjadi sebuah aplikasi Virtual Reality yang dapat digunakan oleh pengguna.

\section{SARAN}

Untuk menjadikan suatu objek nyata atau sebuah konsep menjadi sebuah aplikasi Virtual Reality dibutuhkan ketelitian dalam pembuatannya agar objek yang dibuat dapat menyerupai dengan bentuk aslinya, perlu pemahaman akan pemrosesan objek realitas tiga dimensi yang mendalam serta diperlukan untuk observasi langsung guna mempermudah dalam mendesain tata letak dan perancangan bangunannya. 


\section{UCAPAN TERIMA KASIH}

Pada kesempatan ini, penulis ingin mengucapkan terima kasih yang sebesar-besarnya kepada semua pihak yang telah membantu penulis dalam menyelesaikan penelitian ini, terutama kepada kemenristek dikti yang telah membiayai penelitian ini, kepada bapak-bapak dosen yang ikut terlibat dalam menelitian ini, atas waktu tenaga dan materi yang dikeluarkan dalam prosesnya, semoga Allah SWT membalas usaha dan kerja keras kita semua dan sebuah lading amal untuk kita semua, aamiin.

\section{DAFTAR PUSTAKA}

[1] Kresna Galuh D. 2016, Virtual Reality dan Perkembangannya, https://www.codepolitan.com/virtual-reality-dan-perkembangannya.

[2] Fernandaguns. 2016, System Development Lyfe Cycle (sdlc.2016. http://fernandaguns.ilearning.me/2016/03/08/sdlc-sistem-informasimanajemen/.

[3] Claude Guillot, Hasan Muarif Ambary, and Jacques Dumarçay. 1990, Gramedia Book Publishing Division, Banten.

[4] Pkpt. Provinsi Banten. 2017, http://pdpt.gaismamedia.com/provinsi/banten/.

[5] Baskara Arya Pranata, AK Pamoedji, and Ridwan Sanjaya. 2015, Mudah Membuat Game dan Potensi Finansialnya dengan Unity 3d, PT. ELEX MEDIA KOMPUTINDO, Jakarta.

[6] Rickman Roedavan. 2014, Unity Tutorial Game Engine.

[7] Simas.kemenag.go.id. Sejarah Masjid Agung Banten. 2014, http://simas.kemenag.go.id/index.php/profil/masjid/537/.

[8] Wahyudin Wahyudin, Subandi Wahyudi, and M Isnaeni Agus Robbi. Visualisasi Masjid Agung Rangkasbitung Berbasis 3d dengan Menggunakan Google Sketchup \& After Effect. 